\title{
Control de redundancia visual documental en archivos de televisión:
}

\section{personas y temas}

\author{
Jorge Caldera-Serrano \\ jcalser@alcazaba.unex.es \\ Departamento de Información y Comunicación \\ Universidad de Extremadura
}

\begin{abstract}
Resumen: Se describe el método para desarrollar el control documental de la redundancia informativa audiovisual en el tratamiento, descripción y recuperación de elementos audiovisuales onomásticos y temáticos. Para ello se analiza tanto las características y peculiaridades que representan a la información audiovisual onomástica y temática, así como se presenta una herramienta informática para el control de dichos datos. Esta información deberá estar interconectada, por medio de base de datos relacionales, con la base de datos general de la empresa audiovisual.
\end{abstract}

Palabras claves: redundancia informativa, temas y personas, información audiovisual, archivos de televisión.

Abstract: This paper describes the method used to perform the control of audio-visual documentary redundancy when it comes to handling, describing and retrieving audio-visual onomastic and theme elements. With this purpose in mind. Analysis of the Information Management Systems in the most important television networks to determine their needs in control terms. The characteristics and particularities of the audio-visual onomastic and theme information are analysed, and an IT tool is introduced in order to control the information. This information must be interconnected with the general database of the audio-visual company by means of relational databases. This control method does not exist in televisions analyzed.

Keywords: information redundancy, themes and people, audio-visual information, television archives, information management.

\section{INTRODUCCIÓN}

La evolución de los medios de comunicación ha ido de la mano de la transformación y avance de los medios técnicos. Por ello, y por la necesidad innata del hombre por comunicarse, el primer medio para la transmisión de la información fue el impreso, que hizo posible una gran distribución de la información por medio de la imprenta y posteriormente por las rotativas. Pero la necesidad de información era y es cada vez mayor, por lo que hubo de adaptar diferentes inventos al desarrollo de un invento por el cual se podía transmitir información por medio de ondas. La radio fue uno de los grandes avances tecnológicos y de democratización de la información en nuestra sociedad. Pero sin duda alguna la televisión ha 
logrado convertir la idea de MacLuhan - la pertenencia a una aldea global, la existencia de una tribu televisiva - en una realidad, ya que en torno a dicho medio de comunicación se reúnen familias, amigos y grupos con intereses comunes tanto para acceder a la información como para entretenerse.

Los medios de comunicación están conformadas por grandes empresas que controlan y acceden a la información por medio de un método cercano al monopolio, que controlan tanto medios de información impresos como radiofónicos, siendo actualmente la televisión el medio por el cual se observan las luchas más encarnizadas entre estas grandes empresas.

El cuarto poder accede, difunde y conserva gran cantidad de información, información dispersa temáticamente y de una amplia diversidad de formatos y soportes. Para el control de tan importante activo empresarial se han conformado en la práctica de la totalidad de las cadenas televisivas (a excepción de las cadenas locales) el servicio de documentación que atiende a las necesidades informativas de los periodistas del medio, entre otras funciones (Caldera; Arranz, 2013).

Dichos servicios documentales cuentan con gran importancia en las empresas audiovisuales, tanto es así que suelen estar integradas dentro de la propia redacción, y su personal y la labor desarrollada es cada vez más reconocida. La estructura de la documentación de estas empresas suele ser compleja y de dispar organización.

\section{LAS BASES DE DATOS DE LOS ARCHIVOS DE TELEVISIÓN.}

Los centros de documentación son el elemento visible de un gran entramado documental en el que se enjugan las diferentes tipologías documentales, los soportes más variados con las necesidades más disímiles. La importancia de las tecnologías de la comunicación y la difusión mediata para las empresas comunicativas es igualmente relevante que el desarrollo de la computación para una correcta gestión documental y, muy especialmente, para un rápido acceso al material requerido por los periodistas.

La informatización de las estructuras documentales es una realidad, realidad que sustenta un intercambio fluido de la información entre documentalistas y periodistas, que hace que pueda conservarse y accederse a la información por medio de una serie de parámetros establecidos y pactados por ambos. De este pacto, en el que la comunicación y el entendimiento son imprescindibles, surgen las estructuras conceptuales de las bases de datos que albergarán la información sustituta del documento original.

Las bases de datos actuales están implementadas y desarrolladas con criterios y filosofía analógica (en cuanto al soporte y tratamiento documental) y aún existe graves 
problemas, sobre todo mentales y también técnicos, para desarrollar dichas herramientas documentales atendiendo a dichas realidades. Tanto es así, que muchas cadenas que trabajan con material digital no han abordado una clara reconversión de su gestión documental.

Estas bases cuentan con información documental para controlar los temas, los lugares, los aspectos físicos de la pieza audiovisual, una descripción en texto libre, elementos derivados de la producción, emisión, y evidentemente, todos los elementos relacionados con personas físicas y entidades que aparecen en las imágenes.

\section{CAMPOS ONOMÁSTICOS, TEMÁTICOS Y SU CONTROL.}

La identificación de los sujetos protagonistas de la información resulta absolutamente imprescindible a la vista de la reiterada solicitud de material audiovisual por parte de los usuarios por personajes visualizados. Aunque la recuperación temática es la más requerida para consultas atemporales.

La tarea de identificación de información onomástica no resulta nada fácil al no existir herramientas audiovisuales ni tesauros icónicos que nos indiquen a qué personaje tenemos en nuestros reproductores. Igual pasa con la información temática visualizada (no tema de la información, sino los descriptores de lo que observamos en las imágenes). Las referencias culturales y la experiencia profesional suelen ser los dos aspectos vitales para una correcta identificación de los personajes y temas, así como una actitud de investigador documental para conseguir el nombre completo de ese personaje que resulta imposible identificar.

Existen software, aún en desarrollo, que intentan identificar a los personajes visionados en el material por medio de parámetros biométricos, aunque no esté ni mucho menos estandarizado por los problemas técnicos. Mientras que para la descripción de información temática está absolutamente en manos de los documentalistas.

Los principales campos onomásticos/temáticos con los que cuentan las bases de datos televisivas son:

- Personas física o jurídica/temas visualizada en la imagen.

- Persona física o jurídica/temas referenciada en el sonido.

La forma tradicional de control se centra en un control de autoridad de los personajes aparecidos y referenciados en la información. Pero para la información temática el control se suele realizar por medio de clasificaciones, tesauros o listas de descriptores.

Controlando la redundancia de la información audiovisual: personas y temas.

En un artículo anterior (Caldera-Serrano, 2007) en el que se analiza la presencia de personajes en los medios, se observa que existen personajes aparecidos en un hecho noticioso puntual, aislado. Una noticia ocurre como reflejo de una sociedad por acciones sociales, 
económicas, deportivas o de cualquier otra índole. Un accidente de aviación puede contar con una relación temática con accidentes anteriores, sin embargo el hecho en sí mismo es único, irrepetible e individual. Dicho acontecimiento provocará la generación de una serie de informaciones a raíz de la anterior. Recordamos una realidad: la existencia del periodismo declarativo; casi nunca la televisión se encuentran en el lugar del acontecimiento, por lo que se contará con reacciones, comentarios, discursos relacionados con el suceso, etc. Los personajes relacionados con este hecho noticioso serán noticia durante unos días o semanas, pero después su presencia será nula, salvo que el personaje sea conocido por cuestiones de representación relacionadas con el hecho.

No obstante, existe otra realidad y es que existen personajes relevantes para la sociedad: primeros ministros, monarcas, dirigentes políticos de notable importancia, deportistas, cuentan con una presencia prácticamente continua en la cadena. No significa que sean siempre los personajes principales de la información, sin embargo deben y tienen mucho que contar ante las diferentes noticias. También existe un momento en que la presencia constante deja de ser real derivado del cese de su actividad, ya sea política, deportiva, social, etc., lo que provoca la ausencia permanente en los medios de comunicación.

Esto provoca una redundancia (Drew, 1987) onomástica clara, al contar información casi a diario de algunos personajes, lo que provocaría graves problemas de ruido documental sino controlamos su incorporación al archivo audiovisual.

Esta selección en el material es obligada por diversos motivos tales como la escasez de recursos humanos, la necesidad de reutilización del material para las grabaciones, lo complicado de la gestión documental del material televisión, y especialmente importante para este trabajo la REDUNDANCIA INFORMATIVA VISUAL, ya que dicha redundancia dificulta la comprensión de los contenidos audiovisuales (Matsukawa, 2009).

Sobre la conservación específicamente de elementos onomásticos han de tenerse en cuenta, además de los señalados, otros aspectos tales como los cambios en el aspecto físico de los personajes, es decir, no sólo nos referimos al paso del tiempo y al irremediable envejecimiento, sino también a las mutaciones en el aspecto físico de muchos de los personajes.

Aunque puede parecer contradictorio, con la información temática (Caldera-Serrano, 2010) existe un problema similar. La información es cíclica y se mueve por modas informativas. Es cíclica desde el momento que por medio de las agendas informativas podemos adelantarnos a informaciones antes de que se produzcan: atascos en las salidas de vacaciones, oleadas de viento y frío en invierno, conmemoración de fechas señaladas. Y nos referimos a las 
modas informativas ya que durante cierto tiempo una información podrá estar en la palestra dejando de estar simplemente porque ya no interesa (¿al telespectador o al periodista?).

Otro elemento, derivado del anterior, es la necesidad de contar con información acorde a la temporada del año para que pueda parecer real. Les indico un ejemplo: una solicitud en época veraniega no podrá ser resuelta ofreciendo material de un personaje con abrigo y gorro de lana. La coherencia visual debe primar por encima de parámetros incluso estéticos cuando se desea que el material pase por actual.

Con todo ello, presentamos una ficha de control de selección de personas, que deberá ser implementada de manera computacional. A partir de dicha ficha organizaremos la selección documental.

\section{Ficha de Control de Selección de Personas}

\section{Nombre}

Entidad

\section{CONTROL TEMPORAL}
Año
Fecha

Hiperenlace

\section{DESCRIPCIÓN}

Recurso

Total

Invierno

Verano

Interior

Figura 1. Ficha de control de selección de personas

Se indica en primer lugar, el Nombre de la persona física o la Entidad (así como la entidad relacionada con el personaje), lo cual debe estar relacionado con el índice de control de autoridades.

Posteriormente se indica el año como la fecha de la última imagen conservada del personaje o entidad, conservando la información de registros anteriores. Junto a la fecha se indicará el enlace al documento electrónico para poder visualizarlo por medio de intranet. De todas maneras, en la DESCRIPCIÓN se ofrecerá información para determinar si es un recurso o 
un total, así como condiciones atmosféricas o de vestimenta (Invierno/Verano). En el caso de información realizada en estudio o en interior las condiciones atmosféricas se anulan.

Se denominan totales cuando lo que interesa conservar es la locución del personaje, como declaraciones, ruedas de prensa, entrevistas; mientras que denominados recursos cuando se observa al personaje realizando una acción, como subiendo al coche, saludando a ancianos, besando a niños, jugando al tenis.

Recordamos que tanto las noticias aisladas como en la información en que los personajes están relacionados con diferentes eventos son redundantes visualmente, por lo que no deberá controlarse y conservarse toda la información generada en torno a éstos. Por ello planteamos la necesidad de conservar recursos y totales de estos personajes en determinadas ocasiones a lo largo de un año (cada empresa deberá organizar su trabajo conforme a sus estadios organizativos).

Para el control de la información temática se utilizará la ficha que a continuación se indica y que estará estrechamente relacionada con el tesauro/clasificación/descriptores libres que utilice la cadena.

Ficha de Control de Selección de temas
Tema visual
CONTROL TEMPORAL
Año
Hiperenlace
\begin{tabular}{ll} 
\\
\hline DESCRIPCIÓN \\
Invierno
\end{tabular}

Figura 2. Ficha de control de selección de temas

Sin lugar a dudas el control temático es bastante más complejo al existir diferentes formas de visualizar un mismo tema o acontecimiento. No es lo mismo la descripción SOL que representa a una de las estrellas de la vía láctea que el descriptor POLÍTICA INTERNACIONAL que cuenta con un amplio abanico de imágenes potenciales asociadas a la misma. Por lo tanto, el primer esfuerzo será determinar cuáles de los temas incluidos en nuestras herramientas son potencialmente identificables para este control que será más relevante para el control del ruido documental que para controlar el cambio producido por el paso del tiempo en estos 
temas. Siguiendo con el ejemplo anterior el SOL siempre será el SOL, hoy, ayer, y dentro de 30 años (o eso, al menos, queremos pensar).

Además, esta base de datos para el control de aspectos temáticos, deberá estar relacionada con la de control temático en aquellos casos que las cuestiones temáticas tengan relación con personas, por lo que además estamos dando un paso importante para la creación de relaciones ontológicas para los archivos de televisión.

\section{Las personas físicas y totales.}

Partimos de la concepción de que el periodismo es declarativo, que la inmensa mayoría de las veces que aparece un personaje es hablando y visualmente consiste en un plano medio fijo. Los totales cuentan con una vigencia informativa bastante efímera salvo casos donde lo declarado es a todas luces importantes. También recordamos que el material emitido se conserva y en ellas el periodista selecciona aquellos cortes de voz más interesante del personaje, por lo que el esfuerzo para el control de los totales ha de ser relativo en lo concerniente a los brutos.

No obstante, se deberán conservar al menos en dos ocasiones: una de ellas en interior y otra en exterior, independientemente de la época del año. Esto radica en que el material de interior es mucho más atemporal y se podrá ofrecer independientemente de las condiciones atmosféricas. Queda evidenciado que será utilizado como relleno y que el material sonoro en sí carece de valor para esta información. Conservamos información actual con vistas a un valor de uso futuro.

Se conservará anualmente mientras que el personaje cuente con valor informativo (el valor informativo dependerá de la ponderación de la presencia, su importancia y las solicitudes de los usuarios).

En aquellos casos en los que el personaje no cuenta con tanta validez, se conservará la primera vez que aparezca como personaje principal de la información, volviendo a conservarlo cuando se observa una bajada en la validez informativa. No crean que es complicado dicha observación si tienen presente que el documentalista debe seguir la actualidad de forma continuada.

\section{Las personas físicas y los recursos.}

Los recursos cuentan con mayor utilización que los totales. En éstos se tiene al personaje realizando una acción, y la televisión es por definición movimiento. Los documentos 
cuentan con una duración mayor, lo que se traduce en ciertas ventajas. ¿En qué sentido? Normalmente un documento requerido del archivo para utilizarlo no va a ser requerido en su totalidad, sino que se utilizará breves fragmentos, segundos, por lo que podrán utilizar partes diferentes sin tener que repetir el fragmento visual.

Las acciones (recursos) se conservarán tanto en invierno (con ropa que denote claramente esta visión) como en verano, al igual que se intentará guardar en interior. Dependiendo del personaje y de su potencial reutilización podría llegarse a guardar dos documentos en cada una de las estaciones. Esta decisión tiene que venir marcada por las necesidades de los usuarios y aquellos personajes que son en ese momento "moda informativa". La televisión se mueve evidentemente por modas, de ahí que sea necesario identificarlos para realizar un mayor esfuerzo de selección sobre estos personajes.

\section{Las entidades como unidad de selección y conservación.}

Las entidades pueden igualmente ser visualizadas en un documento. Creo que la ejemplificación ayudará a entenderlo.

- Observando un conjunto de miembros de una entidad desarrollando una actividad que le es propia. Ejemplo: Asamblea de accionistas de una empresa, reunión de un grupo de gerencia, conjunto deportivo en una competición o entrenamiento.

- Identificación de logotipos empresariales.

En este caso, observen que salvo excepciones, la identificación de una entidad por medio de un logotipo no tendría por qué modificarse con el tiempo. La Cruz Roja para todos es un icono de ayuda sanitaria y humanitaria, pero realmente denota una entidad. Igualmente válido sería el escudo de un club, el anagrama de una empresa, etc. Este tipo de identificación salvo su modificación no será necesario un control férreo con la ficha mostrada.

Sin embargo la visualización de un conjunto de miembros de una entidad sí que debe ser controlada, especialmente la de competiciones deportivas, donde es constante el visualizado de estas entidades y no siempre es necesario su conservación. Existen televisiones en las que todos los días ofrecen información de una serie de equipos deportivos, esto no tiene ningún tipo de interés para ser conservados, por lo que se seleccionarían en momentos determinados, como son al comienzo de la temporada, a mediados y al final, así como cuando existan nuevas contrataciones y por lo tanto nuevos rostros inmersos en un conjunto. Y por supuesto, siempre serían en forma de recursos, ya que los totales son propios de personas físicas. 
Esta observación me lleva a otra más interesante y menos obvia. La indicación de una entidad que aglutine a una serie de personas físicas no elimina la opción de indicar a cada uno de estos personajes por separado si son noticias por sí mismos, independientemente que tenga importancia o no su relación con la entidad matriz.

Sólo nos faltaría contestar a una cuestión: ¿cómo llevar a cabo esta labor? La ficha que se ha creado cuenta con la particularidad de que cada vez que un analista conserve una información onomástica deberá realizar el esfuerzo de anotar los parámetros en dicha ficha de control de selección. No es una pérdida de tiempo excesiva, mucho más se tarda en analizar documentos audiovisuales. La consulta a la ficha desarrollada ayudará a determinar si existen imágenes parecidas o muy similares del personaje, así como su actualidad. Esto provoca inicialmente una optimización del trabajo y en la recuperación documental controlando el ruido.

Existen otros elementos a tener en cuenta, como cuestiones legales (derecho a la intimidad, derecho de la infancia), consideraciones técnicas (de calidad de reproducción) y evidentemente de validez potencial para las necesidades futuras del usuario.

Con el fin de facilitar la comprensión y entendimiento de la tabla ofrecemos un ejemplo y su explicación:

Se indica el personaje y la entidad con la que está relacionada. Posteriormente se puede ver el año y fecha en la que se ha conservado la última información sobre el personaje y los datos de descripción asociados. Si se accediera a otros años u otras fechas, la descripción cambiaría para identificar el otro registro. En este caso sabemos que tenemos una declaración, presumiblemente en plano medio, con ropa de verano aunque abril no sea esta estación del año. Por lo tanto, se podrá utilizar esta información para las solicitudes de Zapatero con ropa y entorno atmosférico de verano, sin ser necesaria la conservación de nuevos recursos.

\section{Temas visualizados y su relación con la herramienta documental}

El control del material temático debe de partir de un ejercicio previo: la identificación de los elementos temáticos que se representan con iconos que resulten inequívocos en su transcripción a texto. Este ejercicio no es nada complicado, y dará como resultado un listado de términos útiles para dicha descripción audiovisual temática.

Este listado será sobre el cual se trabaje para el control de la redundancia. Los temas deberán seguir las pautas para personas, por lo que se indicará interior/exterior, si procese, así como la identificación de condiciones climatológicas. 
Por lo tanto, y al ser una herramienta de control de redundancia parcial, deberá estar interrelacionada con la base de datos de la cadena, en lo que respecta a su información temática y su tesauro.

\section{CONCLUSIONES}

La televisión es el medio universal de entretenimiento, y el uso de las nuevas tecnologías no lo están desbancando sino en cierta manera potenciando, aunque esté cambiando claramente el modelo de negocios. Pero el formato televisivo sigue perviviendo, con cambios, por la red Internet.

Esto provoca cada vez mayor cantidad de información en los medios, lo que conlleva la necesidad de mejor y mayor control documental ya que, además, los usuarios son cada vez más exigentes en la información ofrecida por los medios televisivos.

Para ello estimamos importante el control documental del material televisivo, entre ellos el onomástico y temáticos. El control de este material, realizado por medio de una correcta selección y posterior expurgo, se traducirá en elementos que son claves para los 41 periodistas desde el punto de vista de la recuperación documental y de la rapidez desde el punto de vista de la accesibilidad a la información contenida en las bases de datos de las cadenas.

Los beneficios de este control son:

- Rapidez de respuesta. Al ser menor el número de documentos recuperados, el library media podrá decidir qué material facilitar sobre un menor número de documentos.

- Eliminación parcial del "ruido documental". Las consultas tanto por parte del library media como por parte del periodista dará menor número de resultados pero más pertinentes.

- Mayor pertinencia en la recuperación. Los documentos se ajustarán más a los requerimientos reales de los profesionales de los medios de comunicación. 


\section{Bibliografía}

Caldera-Serrano, J. (2007) The Matthew effect and record selection for onomastic ítems in televised audiovisual material. El professional de la Información, 16 (5), 409-415

Caldera-Serrano, J. (2010) Thematic description of audio-visual information on television. Aslib Proceedings, 62 (2), 202-209.

Caldera-Serrano, J., Arranz-Escacha, P. (2013). New documentary selection methods arising from digital information systems employed in television. Investigación Bibliotecológica, 27 (60), $15-26$

Drew, DG., Grimes, T. (1987). Audiovisual redundancy and TV-News Recall. Comunication Research, 14 (4), 452-461.

Matsukawa, R., Miyata, Y., Ueda, S. (2009). Information Redundancy Effect on Watching TV News: Analysis of Eye Tracking Data and Examination of the Contents. Library and Information Science, 62, 193-205. 